\title{
Study on Vortex-Excited Nonlinear Vibration of Casing Pipes in Wave- Current
}

\author{
You-Gang Tang \\ Professor, Department of Naval Architecture and Marine Engineering, School of Architecture Engineering, Tianjin \\ University, Tianjin 300072,, tygwxq@public.tpt.tj.cn \\ Jian-Qin Min \\ Graduate student, Department of Engineering mechanics, Tshinghua University, Beijing 100084. \\ Hong-Yu Zheng \\ Graduate student, Department of Naval Architecture and Marine Engineering, School of Architecture Engineering, \\ Tianjin University. \\ Jia-Yang Gu \\ Graduate student, Department of Naval Architecture and Marine Engineering, School of Architecture Engineering, \\ Tianjin University.
}

Follow this and additional works at: https://jmstt.ntou.edu.tw/journal

Part of the Engineering Commons

\section{Recommended Citation}

Tang, You-Gang; Min, Jian-Qin; Zheng, Hong-Yu; and Gu, Jia-Yang (2003) "Study on Vortex-Excited Nonlinear Vibration of Casing Pipes in Wave-Current," Journal of Marine Science and Technology. Vol. 11: Iss. 1, Article 4.

DOI: $10.51400 / 2709-6998.2275$

Available at: https://jmstt.ntou.edu.tw/journal/vol11/iss1/4

This Research Article is brought to you for free and open access by Journal of Marine Science and Technology. It has been accepted for inclusion in Journal of Marine Science and Technology by an authorized editor of Journal of Marine Science and Technology. 


\title{
STUDY ON VORTEX-EXCITED NONLINEAR VIBRATION OF CASING PIPES IN WAVE- CURRENT
}

\author{
You-Gang Tang*, Jian-Qin Min**, Hong-Yu Zheng***, and Jia-Yang Gu***
}

Key words: casing pipes in the deep water, nonlinear fluid damping, natural vibration, nonlinear vortex-excited vibration.

\section{ABSTRACT}

The vortex-induced nonlinear vibration of casing pipes in the deep water is studied considering the loads of current and combined wave-current. The vortex-induced vibration equation of a casing pipe is set up with considering the beam mode and Morison's nonlinear fluid damp as well as the vortex-excited loads. The approach of calculating vortex-excited nonlinear vibration by Galerkin's method is proposed. The natural vibration characteristics and the vortexexcited vibration response of $170 \mathrm{~m}$ long casing pipe in the $160 \mathrm{~m}$ depth of water are investigated, the resonance induced by wave and the resonance under combined wave-current were investigated, which is shown that the method is practical.

\section{INTRODUCTION}

As depth of water reaches to $100 \mathrm{~m}$ or more than $100 \mathrm{~m}$, the relative stiffness of a casing pipe is reduced, the natural frequency of a casing pipe may be close to shedding frequency of vortex, so the resonance will occur. Because the diameter of casing pipe is much less than length, so a casing pipe can be simplified into the beam model. The interaction between the currents was discussed when the fluid flows through the cylinder, and the wake oscillator-model, correlation-model, and statistical-model were presented for the prediction of dynamics response of cylinders in the uniform flow [7]. Also the wake oscillator-model was employed to predict the vibration of cylinders in the non-uniform flow [3]. The analytical method in the time domain for a riser

Paper Submitted 10/07/02, Accepted 03/05/03. Author for Correspondence: You-Gang Tang.

*Professor, Department of Naval Architecture and Marine Engineering, School of Architecture Engineering, Tianjin University, Tianjin 300072, E-mail: tygwxq@public.tpt.tj.cn.

**Graduate student, Department of Engineering mechanics, Tshinghua University, Beijing 100084.

***Graduate student, Department of Naval Architecture and Marine Engineering, School of Architecture Engineering, Tianjin University. of TLP was developed through simplifying the nonlinear term in the Morison's formula into linear term $[4,6]$. The nonlinear vortex-excited response was calculated for the riser of TLP using the nonlinear fluid damp force and the simple beam model [2]. Based on the beam model with the upper moveable support and fixed support at the bottom, the dynamics response of a riser of TLP was investigated [5]. However the less investigations of vortex-excited vibration have been done for casing pipes in the wave-current, the response mechanisms induced by current and combined wave-current for casing pipes have not been fully understood up to date. The achievements in this paper developed the calculating method of vibration induced by current and combined wave-current for the casing pipe in the deep water, and the vibration behavior of casing pipes are described.

\section{VIBRATION EQUATIONS AND NATURAL MODES}

It is assumed that wave and current flow in same direction $x$, and the cross-section of casing pipe is uniform. The coordinate original point is at the bottom of seas. The analytical model is illustrated in Fig. 1, the upper support represents the link between the lower deck and the casing pipe.

According to Fig. 1, the vibration equation of a

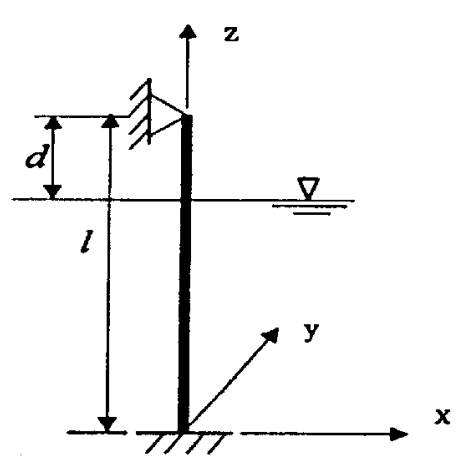

Fig.1. Coordinate system and model. 
casing pipe can be yielded as following

$$
E I \frac{\partial^{4} y}{\partial z^{4}}+m \frac{\partial^{2} y}{\partial t^{2}}+c \frac{\partial y}{\partial t}=F_{y}(z, t)
$$

where, $E$ and $I$ are Young's elastic modulu and bending inertial moment of a casing pipe, respectively; $m$ is the structural mass per unit length; $l$ is the height of a casing pipe; $c$ denotes the damping coefficient; $F_{y}(z, t)$ is the total fluid force per unit length, and

$$
F_{y}(z, t)=F_{L}(z, t)-F_{r}(z, t)
$$

where, $F_{L}(z, t)$ and $F_{r}(z, t)$ denote the vortex-excited force and the fluid damp force due to motion of a casing pipe in the direction $y$, respectively.

$$
\begin{aligned}
F_{L}(z, t) & =\frac{1}{2} \rho D\left(V_{c}+u\right)^{2} C_{L} \cos \omega_{s} t \\
& =K_{L}(z) C_{L} \cos \omega_{s} t
\end{aligned}
$$

and

$$
K_{L}(z)=\frac{1}{2} \rho D\left(V_{c}+u\right)^{2}
$$

where, $\rho$ is the density of water; $D$ denotes the diameter of casing pipe; $u$ is the wave velocity in any depth of water; $C_{L}$ and $\omega_{s}$ are the lift force coefficient and the shedding frequency of vortex, respectively; $V_{c}$ is the current velocity in linear variation with the depth of water, i.e.

$$
V_{c}=a+b z
$$

where, $a$ represents the current velocity on the bottom of sea; $b$ is the coefficient of current velocity.

The nonlinear fluid damp force in the direction $y$ can be expressed in the Morison's formula [2,3]

$$
F_{r}(z, t)=K_{d} C_{d} \operatorname{sgn}(\dot{y}) \dot{y}^{2}+m^{\prime} \ddot{y}
$$

where, $K_{d}=\rho D / 2 ; m^{\prime}$ is the added water mass per unit length, and $m^{\prime}=\rho C_{a} \bullet \rho D^{2} / 4 ; \operatorname{sgn}=+1$ or -1 depend on the negative sign or positive sign of $\dot{y} . C_{d}$ and $C_{a}$ are the coefficients of fluid damp and added water mass, respectively. Here in, $C_{L}=0.6 \sim 2.4, C_{d}=0.4 \sim 2.0, C_{a}$ $=1.0[4,7]$.

As the vibration modes are expressed by Korolov function based on Galerkin's method [1], the vibration deflection can be expanded as following

$$
y(z, t)=\sum_{n=1}^{n} y_{n}(t)\left(E_{\lambda_{n} l} C_{\lambda_{n} z}-D_{\lambda_{n} z}\right)
$$

where, $C_{\lambda_{n} z}$ and $D_{\lambda_{n} z}$ are called as the Korolov function; $E_{\lambda_{n} l}=B_{\lambda_{n} l} l A_{\lambda_{n} l}, A_{\lambda_{n} l}$ and $B_{\lambda_{n} l}$ denote the value of Korolov function as $z=l[1] ; y_{n}(t)$ is the nth mode coordinate. The natural frequencies and vibration mode can be determined according to the boundary conditions of two ends of a casing pipe.

\section{CALCULATION METHOD OF DYNAMICS RESPONSE}

The formula (1) can be simplified into the linear equations employing the Galerkin's method. Substituting the formulas (3 -7) into formula (1), and multiplied by $\left(E_{\lambda_{n} l} C_{\lambda_{n z}}-D_{\lambda_{n} z}\right)$, to integrate the equation in the region $(0, l)$ for the two sides of equation, we have

$$
\begin{aligned}
\ddot{y}_{n} & +\lambda_{B n}^{2} y_{n}+\frac{C_{n}}{m} \dot{y}_{n}+\frac{1}{m} l_{n} D_{n} \\
= & \frac{C_{L}}{m} l_{n} \cos \omega_{s} t \int_{0}^{l} K_{L}(z)\left(E_{\lambda_{n} l} C_{\lambda_{n^{z}}}-D_{\lambda_{n z}}\right) d z \\
& (n=1,2, \ldots, N)
\end{aligned}
$$

and

$$
\begin{aligned}
& \frac{C_{L}}{\bar{m} l_{n}} \cos \omega_{s} t \int_{0}^{l} K_{L}(z)\left(E_{\lambda_{n} l} C_{\lambda_{n^{z}}}-D_{\lambda_{n^{z}}}\right) d z \\
& =A_{c} \cos \omega_{s} t+\left(A_{w} \cos 2 \omega_{w} t+2 A_{c w} \cos \omega_{w} t\right) \cos \omega_{s} t
\end{aligned}
$$

where, $\omega_{w}$ is the wave frequency; $\bar{m}=m+m^{\prime}$; $C_{n}=2 m \lambda_{n} \zeta_{s}, \zeta_{s}$ is the structural damp ratio; and

$$
\begin{aligned}
& \lambda_{B n}^{2}=\frac{E I}{m} \lambda_{n}^{4}, l_{n}=\int_{0}^{l}\left(E_{\lambda_{n} l} C_{\lambda_{n z} z}-D_{\lambda_{n z}}\right) d z \\
& A_{c}=\frac{C_{L} K_{d}}{m} l_{n}\left[\int_{0}^{l}(a+b z)^{2} E_{\lambda_{n} l} C_{\lambda_{n^{z}}}-D_{\lambda_{n^{z}}}\right) d z
\end{aligned}
$$

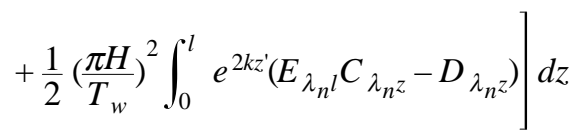

$$
\begin{aligned}
& A_{w}=\frac{C_{L} K_{d}}{2 \bar{m} l_{n}}\left(\frac{\pi H}{T_{w}}\right)^{2} \int_{0}^{l} e^{2 k z^{\prime}}\left(E_{\lambda_{n} l} C_{\lambda_{n z}}-D_{\lambda_{n z}}\right) d z \\
& A_{c w}=\frac{C_{L} K_{d}}{2 m} l_{n}\left(\frac{\pi H}{T_{w}}\right)^{2} \\
& \times \int_{0}^{l}(a+b z) e^{k z^{\prime}}\left(E_{\lambda_{n} l} C_{\lambda_{n} z}-D_{\lambda_{n z}}\right) d z \\
& D_{n}=K_{d} C_{d} \int_{0}^{l} \operatorname{sgn}(\dot{y}) \dot{y}^{2}\left(E_{\lambda_{n} l} C_{\lambda_{n z}}-D_{\lambda_{n z}}\right) d z
\end{aligned}
$$

The dynamics deflection can be obtained solving the formula ( 8 ) by the numerical integration of Runge- 
Kutta. The $\operatorname{sgn}[\dot{y}(z, t)]$ will change with time $t$ and position $z$ in process of integrating $D_{n}$, so $\operatorname{sgn}[\dot{y}(z, t)]$ at $(i+1)$ step is determined by the $\dot{y}(z, t)$ at $i$ step, and $D_{n}$ is solved by the numerical integration.

\section{CALCULATIONS OF EXAMPLE}

The parameters of the example are as following: $a=0.4(\mathrm{~m} / \mathrm{s}) ; b=0.001286(\mathrm{~m} / \mathrm{s}) ;$ Wave length $L_{w}=$ $300 \mathrm{~m}$; Wave frequency $\omega_{w}=0.437(1 / \mathrm{s})$; Distance from the lower deck to the bottom $l=170 \mathrm{~m}$; Diameter $D=0.75 \mathrm{~m}$; Thickness of wall $t=0.02 \mathrm{~m}$; Mass per unit length $m=636(\mathrm{Kg} / \mathrm{m})$; Bending stiffness $E I=$ $0.642 \times 10^{6} \mathrm{kN} \cdot \mathrm{m}^{2} ;$ Structural damp ratio $\zeta_{s}=1.8 \times$ $10^{-3}$. In order to solve the dynamics response employing Galerkin's method, the natural frequencies of casing pipe are calculated and shown in Table 1.

The resonance response excited by current was calculated as only the first term in the right side of formula (9) is considered when $\omega_{s}=0.437(\mathrm{rad} / \mathrm{s})$, and $C_{L}=2.4, C_{D}=0.6$. The mode responses $y_{1}(t), y_{2}(t), y_{3}$ $(t)$ and $y_{4}(t)$ are shown in Fig. 2.

The first mode response $y_{1}(t)$ is larger than the response of other modes from Fig. 2 as $\omega_{s}=\lambda_{1}$. If $\omega_{s}=\lambda_{2}, y_{2}(t)$ is larger than one of other modes, but the response amplitude of second harmonic resonance is less than the amplitudes of first harmonic resonance.

The Fig. 3 shows the vortex-excited resonance induced by combined wave-current when $\omega_{s}=\omega_{w}=\lambda_{1}$.

It is known from Fig. 3 that the modes response induced by wave-current greatly increase, and the nonlinear behaviors of response are very complicated, which can be explained based on formula (9). Only if current is considered, the resonance frequency is $\omega_{s}$; but when the combined wave-current is considered, the resonance frequencies are $\omega_{s}, 2 \omega_{w} \pm \omega_{s}$ according to the formula (9), $2 \omega_{w} \pm \omega_{s}$ are called as the frequencies of composite resonance. The frequencies of composite resonance result in the increase in the response induced by combined wave-current.

The mode responses of bending moment at the bottom for combined wave-current are illustrated in Fig. 4.

The ratios of higher order mode (Order No. > 1) responses to first mode response are $20 \%, 4 \%, 1.2 \%$, respectively from Fig. 3 for deflection response. $\mathrm{But}$ the ratios of higher order mode responses to first mode response are $64 \%, 28 \%$ and $17 \%$ respectively from Fig. 4 for bending moment response, which is shown that the effect of higher modes on bending moment is more important than one of higher modes on the deflection. The history responses curves of bending moment and shear force are presented in Fig. 5.

\section{CONCLUSIONS}

The analytical model of nonlinear vortex-excited vibration is suggested for the casing pipes in the deep water, and the calculation approach using Galerkin's

Table 1. Natural frequencies $(R / s)$

\begin{tabular}{ccccc}
\hline Order & $\lambda_{1}$ & $\lambda_{2}$ & $\lambda_{3}$ & $\lambda_{4}$ \\
\hline Frequency & 0.437 & 1.415 & 2.951 & 5.045 \\
\hline
\end{tabular}
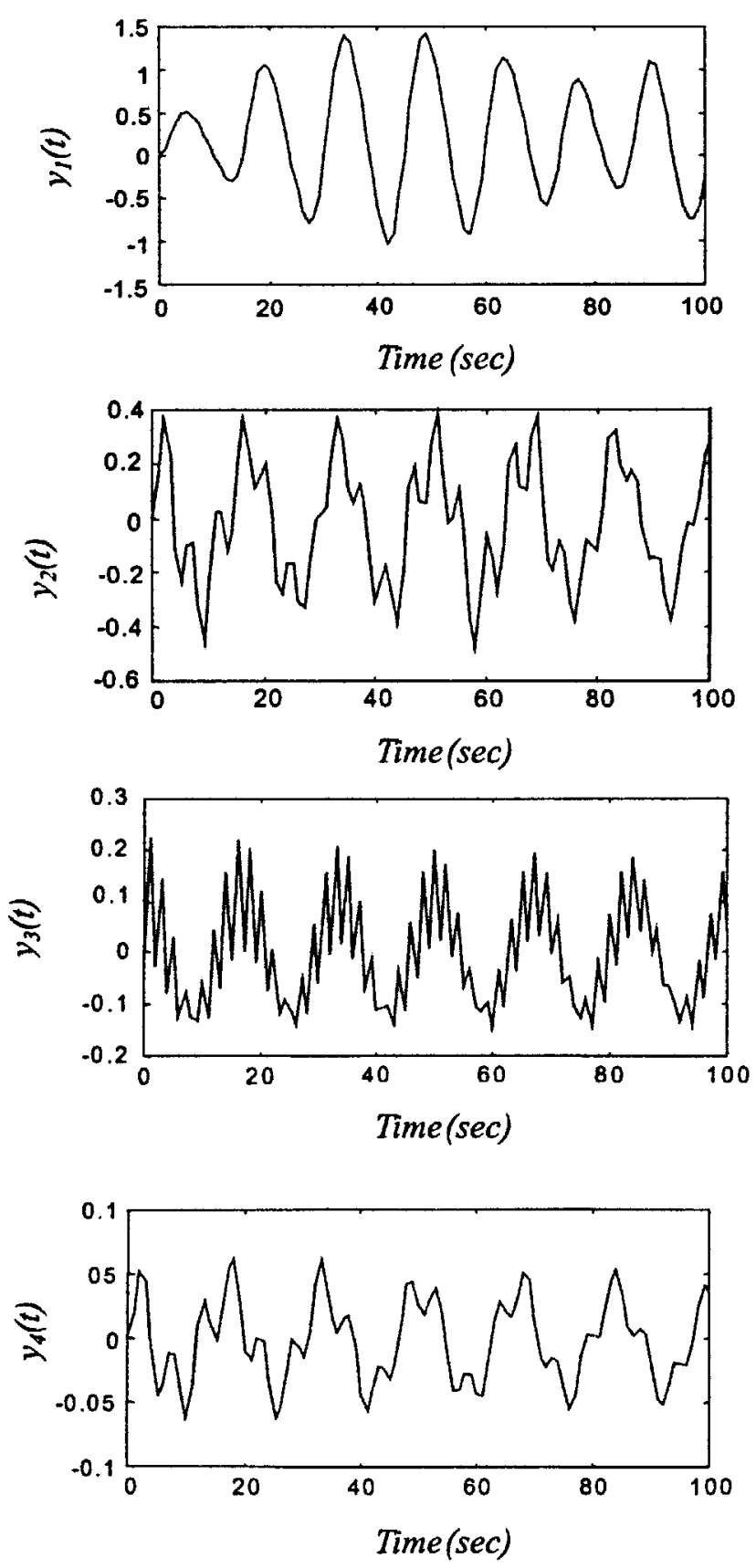

Fig. 2. First harmonic resonance induced by current. 
method is put forward. The follow conclusions are drawn in this paper.

(1) The response of casing pipe greatly increases under combined wave-current due to the composite frequency resonance in combined wave-current.

(2) The combined wave-current should be considered for the calculation of dynamics response as the shedding frequency of vortex is close to the wave
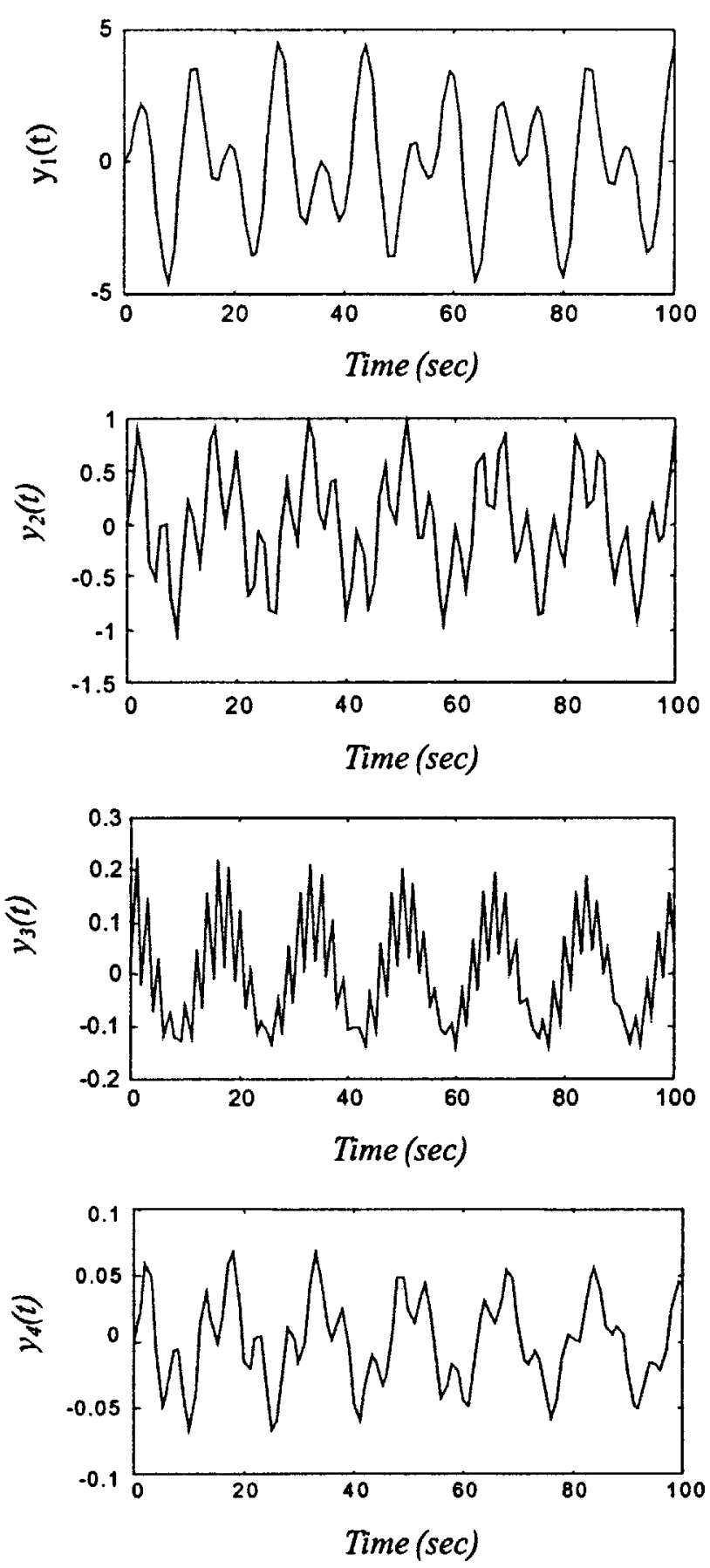

Fig. 3. Resonance induced by wave-current $\left(\omega_{s}=\omega_{w}=\lambda_{1}\right)$. frequency.

(3) In order to get the same accurate both the deflection and the internal forces, the chosen modes for calculation of bending moment should be more than the modes for calculation of deflection.

(4) The paper provides the practical approach for analyzing dynamics strength of casing pipes.
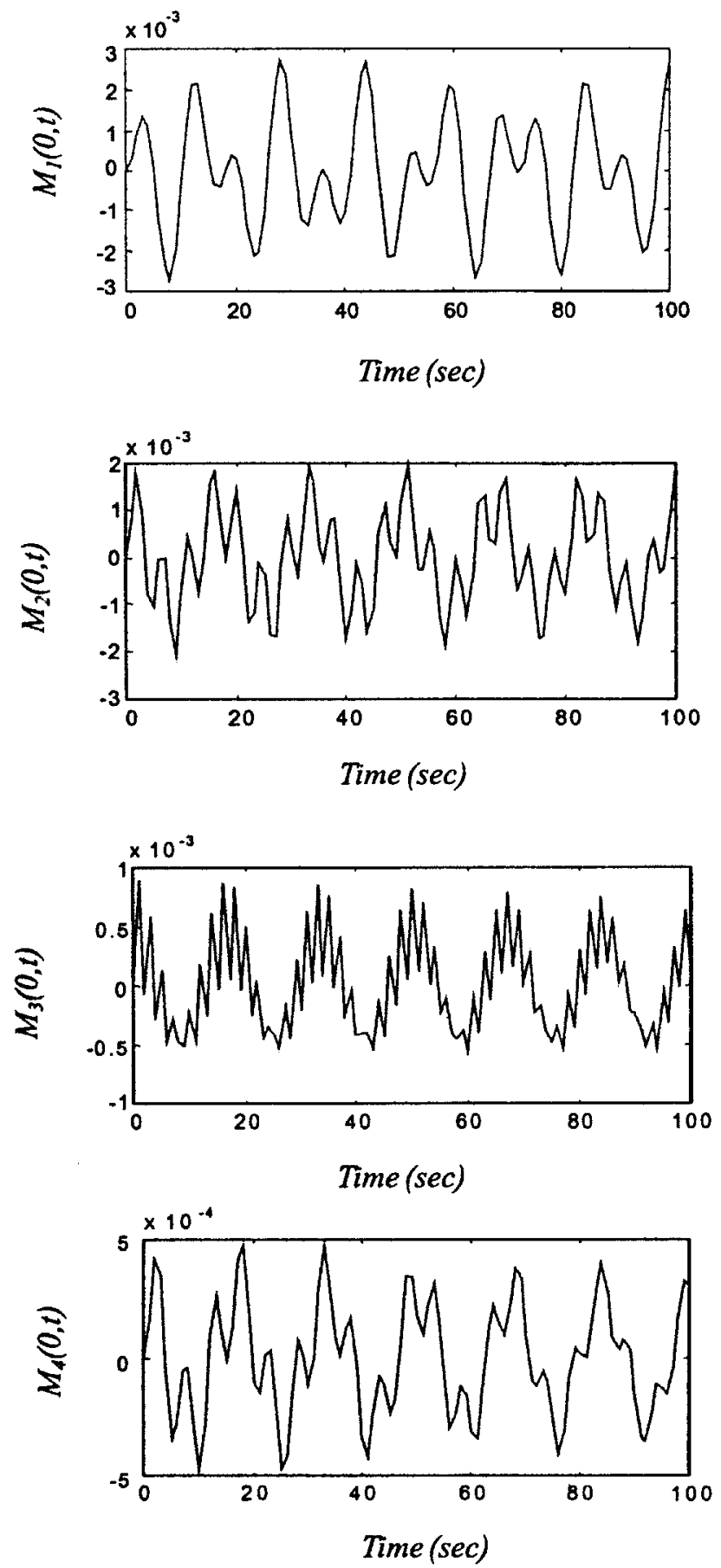

Fig. 4. Mode responses of bending moments under combined wave-current. 

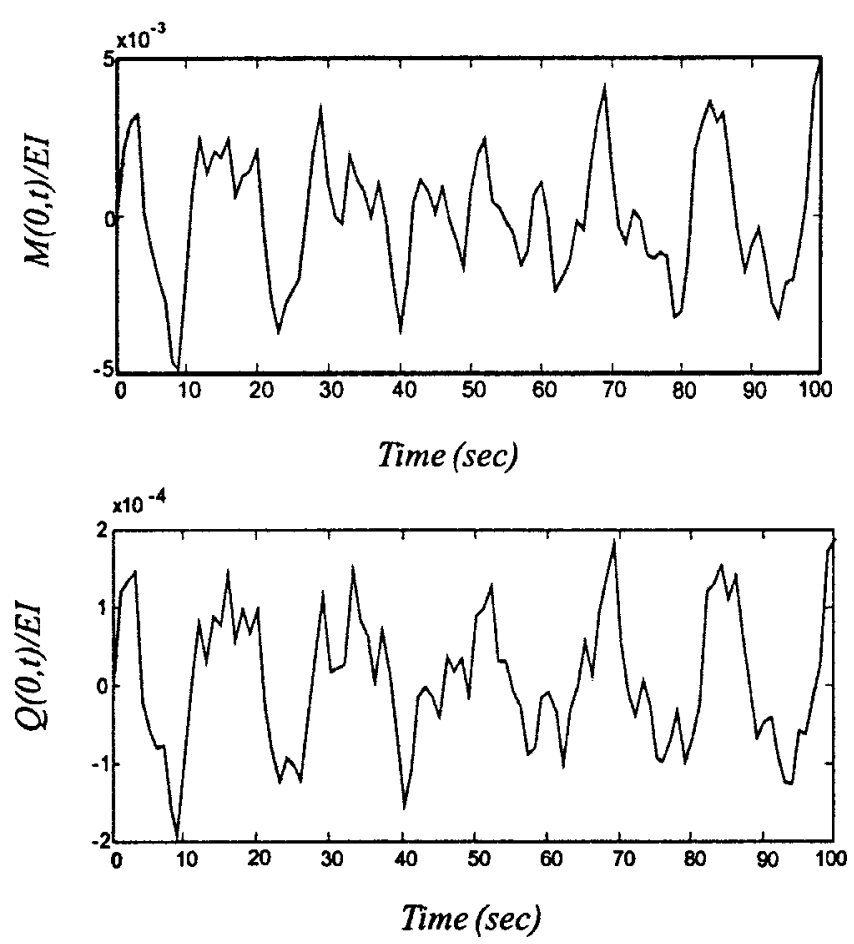

Fig. 5. Response of bending moment and shear force at the bottom.

\section{REFERENCES}

1. Ding, X.C., Structural Dynamics, Beijing: Higher Education Press (1992). (in Chinese)

2. Dong, Y.Q., "Vortex-excited Nonlinear Vibration of Tension Leg of Ocean Platform in Wave and Current," Acta Oceanologica Sinica, No. 3, pp. 121-129 (1994). (in Chinese)

3. Iwan, W.D., "The Vortex-induced Oscillation of Nonuniform Structural System," J. of sound and vibration, Vol. 2, pp. 291-301 (1979).

4. Lyons, G.J. and Petal M.H., "Application of a General Technique for Prediction of Riser Vortex-induced Response in Wave and Current," Transaction of ASME, Vol. 111, pp. 82-91 (1989).

5. Ma, C., Dong, Y.Q., and Hu, Z.M., "Vortex-induced Nonlinear Response of TLP," J. of Tianjin University, No. 6, pp. 701-706 (2000). (in Chinese)

6. Rajabi, F., Zedan, M. F. and Mangiavacchi, A., "Vortex Shedding Induced by Dynamics Response of Marine Riser," Transaction of ASME, Vol. 106, pp. 214-221 (1984).

7. Sparpkaya, T., "Vortex-induced Oscillation: A Selective Review," J. of Applied Mechanics, Vol. 46, pp. 241248 (1979). 